\title{
PRICE VOLATILITY ANALYSIS OF CAYENNE PEPPER (Capsicum frutescens) IN EAST JAVA
}

\author{
Aisyah Mandarsari $^{1^{*}}$, Ratya Anindita ${ }^{2}$, Budi Setiawan ${ }^{2}$ \\ ${ }^{1}$ Post Graduate Program, Faculty of Agriculture, University of Brawijaya, Indonesia \\ ${ }^{2}$ Socio-economics Agriculture Department, Faculty of Agriculture, University of Brawijaya, Indonesia \\ * Corresponding author: aisyahmandarsari@gmail.com
}

\begin{abstract}
The fluctuations in the price of cayenne are still a problem that continues to occur throughout the year. In certain seasons, the increase in the price of cayenne is quite significant, affecting the rate of increase. The government continues to approve and implement the stabilization policy for cayenne prices. In line with this, this study offers to examine the volatility of cayenne prices both at the producer level and at the consumer level. The research also analysis spillover volatility to study the presence or absence of transmission volatility that occurs in the price of cayenne at the consumer level and prices at the producer level. The method used in this study is ARCH / GARCH and GARCH-BEKK. The results show that price volatility at the producer level is high volatility, while price volatility at the consumer level shows a higher value is extreme volatility. The results of this study also show the fact that there is volatility in the price of cayenne at the consumer level with the price of cayenne at the producer level. Information about the results of this study is expected to help stabilize the price of cayenne in the market.
\end{abstract}

Keywords: cayenne pepper, price volatility, spillover volatility

http://dx.doi.org/10.21776/ub.agrise.2020.020.2.5

Received 31 July 2019

Accepted 11 April 2020

Available online 30 April 2020

\section{INTRODUCTION}

The demand of cayenne pepper in the household scale tend to increase annually with the population growth. According to the Ministry of Agriculture data (2017), consumption of cayenne in 2017 is increased up to 413,788 tons. In addition, the demand of cayenne for non-household is also considered high. Non-household consumption requirements for the year 2017 are estimated to increase at 415,154 tons. Fulfilling the consumption needs of national cayenne pepper that continues to increase has been done with increased the production of pepper. Overall, in the period of 20132017, Indonesian cayenne pepper production increased with an average growth of $27.75 \%$ per year. However, this still unable to cope with price fluctuations that continue to occur throughout the year.

The price problem on the commodity of cayenne pepper is still always the case indicates that the fluctuations in the price of cayenne pepper occurred in a certain period. Price fluctuations occur in the market, caused by factors that are influenced by the supply and demand side. Demand or requirement tends to be constant every time, only at any given time, such as at the feast or the day of religion's great demand for cayenne pepper increases by about 10$20 \%$, while the supply is seasonal. Often the price balance occurs in the condition that the amount of goods offered is relatively much less than the number of goods requested. This causes the price of cayenne pepper to be very high. Similarly, the opposite occurs so that the price of cayenne pepper is very low.

One of the effects of the high price fluctuations of cayenne pepper, when the price of chili soar high, it will encourage inflation (increase in prices continuously). As an overview, according to the data of the Central of Statistics (2014), cayenne pepper has a percentage of the increase in the inflation of $0.12 \%$ food ingredients. This increase in inflation is essentially a considerable problem and enough to affect the economic condition of Indonesia. The 
increase in inflation has made economic growth in Indonesia to be hampered. The high price of cayenne pepper can result in the decline of the purchasing power of the people to chili pepper, thus contributing to the decrease in the level of demand for a product. On the other hand, the high price of chili pepper can not be fully enjoyed by the manufacturer because the price of the manufacturer is likely to be determined by the pinder or the middling. Producers or farmers often have limited access and information about the price movements in the market; it also gives the opportunity to the brokers or traders to manipulate the price information at the farmer level (Pertiwi, 2013).

Moreover, high price fluctuations of cayenne pepper will affect the effectiveness of the price stabilization policy of agricultural commodities. As one of the basic needs established by Presidential Regulation (Perpres) Number 71 the year 2015 on the determination and storage of basic needs price and important goods, the Government is obliged to make efforts to ensure the availability of and affordability of cayenne peppers all the time. According to Anindita and Baladina (2017), price variations are becoming a problem during large variations, cannot be anticipated, and create levels from uncertainty and increase the risk of farmers, traders, consumers and governments and also allow impact on the wrong policy. One of the emerging issues associated with the occurrence of price changes or price variations that pose risks and uncertainty introduced as price volatility in the agriculture sector. In other words, price volatility can be interpreted as an inconsistency or tendency that varies from price changes (Gilbert and Morgan, 2013).

As the center of the largest producer of cayenne pepper in Indonesia, East Java province has a big contributed in influencing the price level of the cayenne pepper circulating the market. So complete information about the volatility of cayenne pepper prices in East Java becomes important to support the policy of stabilizing the price of agricultural commodities in Indonesia. As an effort to help producers deal with the risks of price changes that are difficult to predict, this research aims to: (1) Analyze price volatility chili pepper at the producer level in East Java, (2) Analyzing price volatility cayenne pepper at the consumer level in East Java, and (3) Analyzing the volatility of spillover chili pepper between markets at the consumer level with at the producer level in East Java.

\section{RESEARCH METHODS}

This research uses the time series of the monthly average price of cayenne pepper in the East Java period from January 2014 to December 2018. It is a secondary data sourced from East Java Statistical Center (BPS). Data collection is done by a direct survey of BPS East Java.

Volatility analyses the price of cayenne pepper in this research using the ARCH/GARCH model, and for the analysis of spillover volatility using the GARCH-BEKK model. Both models were built with the help of Eviews 9 software. This approach is chosen because this model does not perceive heteroskedasticity as a problem, but it looks heteroscedasticity as a variant to be modeled. Therefore, the estimation using Ordinary Least Squares (OLS) on this model has a low or inaccurate level of trust. This approach not only fixes the lack of conventional methods but also calculates the variant of each term error (Engle 2001). The stages of price volatility analysis and spillover volatility are as follows:

\section{Stationarity test}

In this research, stationary tests were used to test whether price data at the producer level as well as at the consumer level were stationary or not. The stationary test was done with a root test unit using the Augmented Dickey-Fuller test on the price data variable cayenne pepper at the producer level and price data of cayenne pepper at the consumer level. Stationary or not, such data can be viewed through the probability value by using the Eviews program tools. Here are the testing formulas in stationary tests:

$\mathrm{H} 0: \rho \mathrm{k} \neq 0$, the root unit is non-stationary

$\mathrm{H} 1: \rho \mathrm{k}=0$, the root unit is stationary

Test criteria:

a. If the prob < significant value (0.05), reject H0 and $\mathrm{H} 1$ accepted which means that the time series data cayenne prices at the producer level and cayenne prices at the consumer level is the root unit is stationary.

b. If prob> significant value (0.05), then accept $\mathrm{HO}$ and reject $\mathrm{H} 1$, which means that the time series data cayenne prices at the producer level and cayenne prices at the consumer level is the root unit that is not stationary.

The next test is done by using the following test criteria:

a. If the ADF statistic < critical test value, reject H0 and accept $\mathrm{H} 1$, which means that the time series data cayenne prices at the producer level and 
cayenne prices at the consumer level is the root unit is stationary.

b. If the ADF statistic > critical test value, then accept $\mathrm{H} 0$ and reject $\mathrm{H} 1$, which means that the time series data cayenne prices at the producer level and cayenne prices at the consumer level is the root unit that is not stationary.

\section{ARCH Effect Test}

Identifying the existence of ARCH in this study used the Lagrange Multiplier test (ARCH-LM test) using the EViews program tools. An ARCH effect test is performed to see the variance of the error, whether it is constant or not. Data that contains ARCH effect, the data is heteroskedasticity, which is used as an indicator of the initial symptoms of volatility. Meanwhile, data that has a constant variance error, the data is heteroskedasticity. Here are the testing formulas in the ARCH-existence test:

H0: $\alpha 1=\alpha 0=0$

H1: at least one $\alpha \neq 0$

Testing criteria:

a. If probability > the significance value (0.05), then reject $\mathrm{HO}$ and accept $\mathrm{H} 1$, that is where $\mathrm{ARCH}$ is not real or the result of the model has not contained ARCH

b. If the probability < value of significance (0.05), then accept and reject $\mathrm{H} 0 \mathrm{H} 1$, that is, the presence of real ARCH or the model contains ARCH.

3. Analysis of Price Volatility

a. Behavior Analysis volatility using ARCHGARCH models

Equation model of ARCH / GARCH used in this study are:

$$
\begin{aligned}
\sigma^{2} P P & =\alpha_{0}+\alpha_{1} \varepsilon^{2} P P_{t-1}+\beta_{1} \sigma^{2} P P_{t-1}+\varepsilon_{t} \\
\sigma^{2} C P & =\alpha_{0}+\alpha_{1} \varepsilon^{2} C P_{t-1}+\beta_{1} \sigma^{2} C P_{t-1}+\varepsilon_{t}
\end{aligned}
$$

Where:

$\sigma^{2}=$ Variable response (bound) at time $\mathrm{t}$, or the diversity of residual current,

$\alpha_{0} \quad=$ Constant,

$\varepsilon^{2 \mathrm{t}-1}=$ Interest ARCH/volatility in the previous period,

$\alpha_{1}, \beta 1=$ Coefficient estimates,

$\sigma^{2 t-1}=$ Interest GARCH / Diversity residual earlier period,

$P P \quad=$ Price cayenne at the producer level,

$C P \quad=$ Price cayenne at the consumer level,

$\varepsilon_{\mathrm{t}} \quad=$ factors error term in the period to $\mathrm{t}$.

According to Lipetit (2011), the sum of $\alpha 1$ and

$\beta 1$ estimation coefficient on each model indicates the level of volatility. So volatility can be known by looking at the value of $\alpha 1+\beta 1$. In this case, $\alpha$ is the value of $\mathrm{ARCH}$, and $\beta$ is the value of GARCH. Where if $\alpha 1+\beta 1<1$ indicates a low volatility, $\alpha 1+$ $\beta 1=1$ indicates high volatility and $\alpha 1+\beta 1>1$ indicates very high volatility (extremely high volatility).

b. Analysis Calculation Annual Volatility

The measurement of price volatility at the producer and consumer levels in this study uses historical volatility, which is the calculation of volatility using price data in the past (backward-looking). Price volatility is indicated by using standard deviation from the various variations of the price itself. Calculation of yearly price volatility using Microsoft Office Excel tools. Here is the stage in calculating price volatility.

1) Calculation of logarithmic price changes

The calculation of logarithmic price changes is used to determine the value of changes in the logarithmic price both at the price of cayenne pepper at the producer level and price at the consumer level. The calculation formula of the change value of the price logarithm is as follows:

$$
\mathrm{PHJ}=\operatorname{Ln}() \ldots \ldots \frac{p_{2}}{p_{1}}
$$

Where:

$$
\begin{array}{ll}
\text { PHJ } & =\text { Price change in } \mathrm{j} \\
\mathrm{P} 1 & =\text { Price in the previous month } \\
\mathrm{P} 2 & =\text { Price in the current month }
\end{array}
$$

2) Standard Deviation Calculation

Standard deviation is used to determine the variation, which is a measure of the price itself. Here is the formula used in the standard deviation test:

$$
\mathrm{SD}=\sqrt{\frac{\sum(x-\bar{x})^{2}}{n}}
$$

Where:

$\mathrm{SD}=$ The standard deviation (standard deviation)

$\mathrm{x} \quad=$ Change in price

$\bar{x}=$ Average price changes

$\mathrm{n} \quad=$ Number of price data

3) Annual price volatility calculation

The annual price volatility calculation used to determine the annual price volatility by using the following formula:

$$
\text { Yearly price volatility }=S D \cdot \sqrt{12}
$$

Where:

SD = The standard deviation (standard deviation)

4) Spillover Volatility Analysis 
The spillover volatility analysis can be done using GARCH-BEKK model to uncover whether the spillover volatility occurs between the producers and consumer-level prices. Here are the GARCH-BEKK models used to analyze price volatility at the manufacturer's level and the price at the consumer level:

$$
\begin{gathered}
h C P, P P_{t}=c C P, P P+\alpha_{C P, P P}^{2} v_{C P_{t}-1}^{2} v_{P P_{t}-1}^{2} \\
+\beta_{C P, P P}^{2} h C P, P P_{t-1}
\end{gathered}
$$

Where:

$$
\begin{aligned}
& h C P, P P \quad=\text { Conditional covariance relationship } \\
& \text { between prices at the consumer } \\
& \text { level cayenne pepper and cayenne } \\
& \text { prices at the producer level at time } t \\
& \mathrm{C}=\text { constant } \\
& \alpha, \beta=\text { Parameter estimation } \\
& \text { HCP, PPt-1 = Conditional covariance relationship }
\end{aligned}
$$

Volatility spillover at cayenne prices at the producer level and cayenne prices at the consumer level can be determined from the value of squared residuals $\left(v_{C P_{t}-1}^{2} v_{P P_{t}-1}^{2}\right)$ between the price at the level consumer cayenne pepper and cayenne prices at the producer level in the previous period by testing the following formula:

$H_{0}=v_{C P_{t}-1}^{2} v_{P P_{t}-1}^{2}>0$ (positive), volatility spillover occurs between cayenne prices at the consumer level and cayenne prices at the producer level

$H_{1}=v_{C P_{t}-1}^{2} v_{P P_{t}-1}^{2}<0$ (negative), Does not occur volatility spillover between cayenne prices at the consumer level and cayenne prices at the producer level

Test criteria:

a. If the value residual of cayenne prices at the consumer level and cayenne prices at the producer level-1 $\geq 0$ (positive), then reject $\mathrm{H} 1$ and thank $\mathrm{H} 0$ so that it can be said to occur volatility spillover between cayenne prices at the consumer level and cayenne prices at the producer level

b. If the value residual of cayenne prices at the consumer level and cayenne prices at the producer level $\mathrm{t}-1 \leq 0$ (negative), then accept $\mathrm{H} 1$ and reject $\mathrm{H} 0$ so that it can be said does not happen volatility spillover between cayenne prices at the consumer level and the price of chili pepper at the producer level.

\section{RESULTS AND DISCUSSION}

The results of the volatility analysis of cayenne pepper producers and consumers as well as the spillover volatility analysis using a modeling approach ARCH / GARCH and GARCH-BEKK are as follows:

a. Stationarity test

Based on the stationary test using ADF test showed that the price of chili at the level of producers and consumers are not stationary at the current level. The results of the ADF test analysis on the current level are presented in Table 1 below.

Tabel 1. ADF test result at level

\begin{tabular}{lccc}
\hline \multicolumn{1}{c}{ variables } & $\begin{array}{c}\text { Critical } \\
\text { Value 5\% }\end{array}$ & t-stat & Prob \\
\hline Price Producer & -3.487845 & -2.07667 & .5477 \\
Price Consumer & -3.489228 & -3.99812 & .0141 \\
\hline
\end{tabular}

Source: Secondary data is processed, 2019

Description: $* * *=$ significant at the $1 \%$ level

The variable that is not significantly at the $1 \%$ level, meaning that the data contains the root of the unit. This illustrates that the measurement of price volatility will be conducted with the test methods ARCH-GARCH.

\section{b. Determination of ARCH-GARCH Model}

The determination of ARCH-GARCH models done through several stages. According to Kozhan (2010), these stages consist of ARCH effect test, ARCHGARCH analysis of the data, and the last is a diagnostic model. These stages in more detail will be explained as follows: 
1) Test ARCH Effect

Based on the test results of the ARCH test, it is known that the probability of the ARCH effect on the variable data price cayenne prices at the producer level and the consumer has a value less than the significance level of 0.05 . This illustrates that the existence of a real ARCH effect or model contains $\mathrm{ARCH}$ as in Table 2 below.

Table 2. ARCH test results effect

\begin{tabular}{lcccc}
\hline \multicolumn{1}{c}{ variables } & F-stat & $\begin{array}{c}\text { Obs * R- } \\
\text { squared }\end{array}$ & Prob. F (1,57) & $\begin{array}{c}\text { Prob. } \\
\text { Chi-Squared }\end{array}$ \\
\hline Price Producer & 94.9086 & 36.8616 & 0.0000 & 0.0000 \\
\hline Price Consumer & 11.6670 & 10.0245 & 0.0012 & 0,0015 \\
\hline
\end{tabular}

Source: Secondary data is processed, 2019

2) Analysis of ARCH-GARCH to Data

ARCH-GARCH analysis begins with the selection order of $p=1$ and $q=1$. Order $p$ is the order of $\mathrm{ARCH}$, and $\mathrm{q}$ is the order of GARCH. The next step is to check if there are components of both $\mathrm{p}$ and $\mathrm{q}$ with a higher-order, which is also significant through an overfitting process. According to Subramaniam et al. (2013), the overfitting is to re- analyze the data using the higher-order $p$ and $q$ of the order $\mathrm{p}$ and $\mathrm{q}$ that have been tested. Results of the overfitting process that has been done obtained the best model with the value of GARCH (2.2) for the price volatility of producers and GARCH (1.1) for the volatility of consumer prices with details listed in Table 3.

Table 3. ARCH-GARCH analysis results

\begin{tabular}{cccc}
\hline GARCH & Variables & Coefficient & probability \\
\hline \multirow{2}{*}{ GARCH } & $\mathrm{C}$ & $-158,560.5$ & 0.0000 \\
$(2,2)$ & Resid $(-1)^{\wedge} 2$ & 0.762509 & 0.0000 \\
& Resid $(-2)^{\wedge} 2$ & -0.987659 & 0.0000 \\
& GARCH $(-1)$ & 0.752688 & 0.0000 \\
GARCH & GARCH $(-2)$ & 0.589209 & 0.0000 \\
$(1.10$ & $\mathrm{C}$ & 20142586 & 0.2052 \\
& Resid $(-1)^{\wedge} 2$ & 1.305176 & 0.0003 \\
\hline GARCH $(-1)$ & 0.028051 & 0.7541 \\
\hline
\end{tabular}

Source: Secondary data analyzed, 2019

3) Model Evaluation

The next step after a significant model is obtained, then the next step is to test the model. Model testing was conducted by means of test data and heteroskedasticity test data. The results of the data conversion test can be seen in Table 4 .

Table 4. The normal data test

\begin{tabular}{ccc}
\hline Model & Series & $\begin{array}{c}\text { Standardized residuals sample } \\
\text { observation }\end{array}$ \\
\hline GARCH $(2,2)$ & Probability & 0.387960 \\
\hline GARCH $(1,1)$ & Probability & 0.460881 \\
\hline
\end{tabular}

Source: Secondary data is processed, 2019

Notes: $*$ significant at $\alpha=0.05$

Based on Table 4, it can be seen that the value of probability is 0.387960 and 0.460881 , where the value obtained $>$ the signification number (0.05). This indicates that the residual is normal. It is said to be normal when the receipt is around the diagonal line and follow the direction of the diagonal line or the histographic chart. Further examination of the residual heteroskedasticity is presented in Table 5.

The probability is resulting from the tests that have been done worth 0.3752 and 0.6399 . The value obtained is greater than the significance level (0.05). This indicates that there has been no problem heteroskedasticity on the selected model. 
Table 5. Test results heteroskidastity

\begin{tabular}{lccc}
\hline \multicolumn{4}{c}{ GARCH $(2,2)$} \\
\hline F-statistic & 0.798838 & Prob. F $(1,57)$ & 0.3752 \\
Obs * R-squared & 0.815439 & Prob. Chi-Square (1) & 0.3665 \\
\hline \multicolumn{4}{c}{ GARCH $(1,1)$} \\
\hline F-statistic & 0.212239 & Prob. F $(1,57)$ & 0.6468 \\
Obs * R-squared & 0.218871 & Prob. Chi-Square (1) & 0.6399 \\
\hline
\end{tabular}

Source: Secondary data processed, 2019

c. Volatility in the price level of Producers and Consumers

1) Volatility Price Level Manufacturers

Based on the testing that was done, it can be formulated equation volatility in producer prices as follows:

$$
\begin{aligned}
& \sigma^{2} P P t=-158,560.5+0.762509 \varepsilon^{2} P P t-1- \\
& 0.987659 \varepsilon^{2} P P t-2+0.752688 \sigma^{2} P P t-1+ \\
& 0.589209 \sigma^{2} \text { PPt-2 }
\end{aligned}
$$

Note: $\mathrm{PP}=$ Price Level Manufacturers

Based on price volatility equations at the producer level can be noted that price volatility has a high value of 1 . As explained in the volatility analysis method chapter that when $\alpha+\beta=1$ will indicate that there is high volatility (Engle, 1982). Lepetit (2011) also explained that if $\alpha+\beta=1$ then the high volatility occurs while $\alpha+\beta<1$ Then the volatility occurs low. According to Brook (2011), the summation value of the coefficient closer to one indicates the occurrence of interference, it will greatly affect the price volatility. It is also explained that the volatility that occurs in the current time will lead to forecasting volatility that occurs in the future, where such volatility will occur with high and long periods of time.

2) The volatility of Consumer Price Level

Based on the testing that was done, it can be formulated equation volatility of consumer prices as follows:

$$
\begin{gathered}
\sigma^{2} C P t=29473.47+1.305176 \varepsilon^{2} C P t-1+ \\
0.018344 \sigma^{2} C P t-1
\end{gathered}
$$

Based on the equation above, it can be noted that the price volatility of cayenne pepper at the consumer level has a very high value of 1.3. It is evidenced by the volatility value of more than 1 (Engle, 1982). Volatility in consumer levels tends to fluctuate higher compared to volatility at the producer level. This is because the consumption of cayenne pepper for households and the industry is increasing rapidly.

Price volatility at consumer levels is also influenced by several other factors. Factors such as the length of supply chain and the high margin distribution from the initial purchase at the manufacturer level to the consumer, so it is considered inefficient and causes high prices at the end consumer level. According to Bakari (2013), mention that the disturbance factor of supply and demand is one of the things that greatly affect the amount of price volatility that occurs. In research, it is also suspected that the demand disruption factor is one of the causes of price volatility that occurs.

d. Volatility Spillover Between the Producer Price and Consumer Price cayenne pepper in East Java

Volatility spillover from this study shows the effects of the volatility of securities prices or transmission as a result of volatility that is difficult to predict (unpredictable) at various levels of cayenne prices in East Java, both at the producer and consumer. Equation volatility spillover cayenne prices in East Java at the level of producers and consumers are presented as follows:

Table 6. Results of volatility spillover price level producers and consumers

\begin{tabular}{lcc}
\multicolumn{1}{c}{ variables } & equation Model & Spillover \\
\hline The producer price and & $h C P, P P_{t}=18312228,697+1,54793812_{C P, P P}^{2} v_{C P_{t}-1}^{2} v_{P P_{t}-1}^{2}$ & Spillover occurs \\
consumer & $+0,1650557866_{C P, P P}^{2} h C P, P P t-1$ &
\end{tabular}

Source: Secondary Data analyzed, 2019

Where:

$\mathrm{CP}=$ Consumer Price Level

$\mathrm{PP}=$ Price Level Manufacturers 
Based on the analysis of volatility, spillover 1.54793, or coefficient values obtained are positive. This shows that there is volatility spillover on consumer prices with prices at the producer level. According to Rapsomanikis and Harriet (2011), if the value of the variance of the data linkage price volatility is positive, then it can be said to occur among these variables volatility spillover or transmission of price volatility. This proves that the volatility of prices at the consumer level and volatility of prices at the producer level are interrelated because of a transmission of volatility between the two.

\section{CONCLUSION}

Based on the results of the research that has been done, the conclusion of this weaver among is the price of cayenne pepper level producer experiencing high volatility (high volatility) with the number of estimates of ARCH and GARCH worth 1. This indicates that the volatility that occurs in the current time will lead to forecasting volatility that occurs in the future, where such volatility will occur with high and long periods of time. Price volatility of the consumer level cayenne pepper showed a very high volatility value (extreme volatility) with a number of estimates of ARCH and GARCH worth 1.3. Volatility at the consumer level generally fluctuates higher compared to volatility at the producers due to the consumption of cayenne pepper for both households, and the industry is increasing rapidly. Spillover volatility occurs between the price of the cayenne pepper level and the consumer with an estimated coefficient value of 1.54. This proves that price volatility at the consumer level and price volatility at the producer level is interconnected.

\section{REFERENCES}

Anindita, R and Baladina, N. 2017. Products Marketing of Agricultural Products. Andi, Yogyakarta

Bakari, Yuliana. 2013. Analisis Volatilitas Harga, Transmisi Harga, dan Volatility Spillover Pada Pasar Dunia Crude Palm Oil (CPO) dengan Pasar Minyak Goreng di

$\begin{array}{llr}\text { Indonesia. } & \text { Malang: } & \text { Program } \\ \text { Pascasarjana } & \text { Fakultas } & \text { Pertanian, } \\ \text { Universitas Brawijaya. } & \end{array}$

Brooks, Chris. 2008. Introductory Econometrics For Finance Second Edition. New York: Cambridge University Press.

BPS. 2018. Production, Area Harvested and Yield cayenne pepper in Indonesia. Jakarta: The Central Bureau of Statistics.

Engle, R.F. (1982). Autoregressive Conditional Heteroskedasticity with Estimate of the Variance Of U.K Inflatio. Econometrica 50: 987-1008.

Engle R. 2001. The use of ARCH/GARCH models in applied econometrics. J Econ Perspect. $15: 157168$

Khozan, Roman. (2010). Financial Econometrics. Ebooks: Ventus Publishing.

Lepetit dan Isabelle Piot. (2011). Price Volatility and Price Leadership in the EU Beef and Pork Market. Workshop on Methods to Analyse Price Volatility. Institute for Prespective Technological Studies (IPTS), Join Research (JRC), European Comission. Spain.

Pertiwi, Vi'in Ayu. 2013. Analysis of Volatility, Transmission Price and Volatility Spillover Shallots (Allium ascolanium L.) in East Java. Malang: Graduate, University of Brawijaya.

Rapsomanikis, George and Mugera H. 2011. Price Transmission and Volatility Spillovers in Food Market. Journal for Safeguarding Food Security in Volatile Global Markets. Publishing by Food and Agriculture Organization of The United Nations. Rome

Subramaniam, Nava., L. McManus. dan Jiani Zhang. (2013). "Corporate Governance, Firm Characteristics, and Risk Management Committee Formation in Australia Companies". Managerial Auditing Journal 24 (4): 316-339. 
This page is intentionally left blank 